level for female teachers about asthma was fairly higher than male ones. According to the education level, there was not a remarkable difference. According to the school types, public school teachers were somewhat lower than private school teachers. Asthma experience caused a meaningful increase in teachers' asthma knowledge level. According to the career duration between the teachers, the experienced teachers had more information about the triggers, whereas less experienced teachers were evaluated as well-informed about emergency medical care during the attack.

Conclusions The teachers having the knowledge about asthma reduce familial anxiety and school abstinence rate. This survey helps prepare a guideline for the next education programs and seminars amongst teachers.

\section{PREVALENCE OF HYPOSPADIAS IN DENMARK: A REGISTRY BASED POPULATION STUDY FROM 1986-2009}

doi:10.1136/archdischild-2012-302724.0377

${ }^{1} \mathrm{~KB}$ Nissen, ${ }^{2} \mathrm{~A}$ Udesen, ${ }^{3} \mathrm{E}$ Garne. ${ }^{1}$ Pediatrics, Hans Christian Andersen Childrens Hospital; '2Department of Plastic Surgery, Odense University Hospital, Odense; ${ }^{3}$ Department of Pediatrics, Division of Neonatology, Kolding, Denmark

Background Over the last decades the prevalence of hypospadia has been reported with increasing trends, but with widespread variation across countries.

The aim of this study was to determine the prevalence and trend of hypospadia over 23 years in a Danish population.

Design Population-based study of all infants born in the period 1986-2009 in Funen County, diagnosed with hypospadias and reported to the EUROCAT registry of congenital anomalies.

Cases were included only if surgery for hypospadias was performed or planned.

Results 201 cases of hypospadias were registered in 1986-2009 with an overall prevalence of 15.2 pr 10000 births. (95\% CI: 12.2 to 17.9). The prevalence of hypospadias increased from 4.1 in 1986 to 15.1 in 2009 with a peak prevalence in 2002 at 25.5 per 10000 births. The increase in prevalence was significant comparing the years $1986-1999$ to $2000-2009$ ( $p<0.001)$.

From 2000-2009 it was possible to specify the degree-of-severity of hypospadia. Infants with hypospadia as an isolated congenital anomaly were more likely to have a mild form of hypospadia (93\%) while cases with associated congenital anomalies had a lower proportion of mild hypospadias (58\%) $(\mathrm{p}<0,001)$.

Conclusion The prevalence of hypospadias has increased in a Danish county from 1986-2009 although from 2002 the rate seems to be levelling off. The aetiology of isolated hypospadias is multifactorial (paternal, maternal, endocrine and environmental factors). It is mandatory to have a comparable surveillance system in place to assess rates properly between countries in order to monitor changes in potential risk factors.

\section{GROWING UP HEALTHY IN GHANA II: SOCIOECONOMIC AND SPATIAL PREDICTORS}

doi:10.1136/archdischild-2012-302724.0378

B Reime, A Hahn, B Kreuels, W Loag, 0 Maiga, J May. Infectious Disease Epidemiology, Bernhard-Nocht-Institute for Tropical Medicine, Hamburg, Germany

Background and Aims Especially in resource poor settings measures for health promotion should be guided by evidence to channel expenditures according to populations' health priorities. Our aim was to identify predictors for infants' health amenable for short or midterm change to guide health policy decision making in Ghana. Methods This part of the Intermittent Preventive Treatment in Infants Trial used socioeconomic, behavioral and knowledge-related data that were collected on recruitment with interviews in the local language. Spatial data on the infants' residence area were measured by handheld global positioning system (GPS) receiver. We tested the association between these factors and health in bivariate and multivariable analyses adjusted for each other and for genetic and clinical factors.

Results In bivariate analyses, maternal age, financial status, TV, radio, refrigerator and kitchen in the house, malaria knowledge, effective protection against mosquitos and the villages' distance to the next hospital were related to health but birth order and water source were not. In multivariate analyses, infants from well-off families were twice as likely to grow up healthy $(\mathrm{OR}=2.03,95 \%$ $\mathrm{CI}=1.32-3.54)$ than infants from poor families. Type of mosquito protection and distance to hospital also were related to health.

Conclusions Independently of the child's genetic traits, effective protection against mosquitos and access to hospital may be related to better health outcomes in this area in Ghana. Further studies should explore how access to health services can be improved in remote settings. In the meantime, investment in effective mosquito protection may support growing up healthy in Ghana.

\section{HEALTH DISPARITIES IN WELL CHILD VISIT IN A COMPREHENSIVE PEDIATRIC CARE CENTER IN UNITED STATES: DOES INSURANCE MATTER?}

doi:10.1136/archdischild-2012-302724.0379

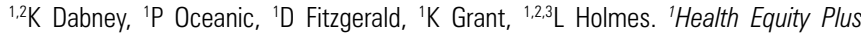
Inclusion; ${ }^{2}$ Orthopedic Department, Nemours/A.I. Dupont Children Hospital, Wilmington; ${ }^{3}$ Biological Sciences, University of Delaware, Newark, DE, USA

Background and Aims The Center for Disease Control and Prevention (CDC) provides guidelines on age-appropriate well child visist. We aimed in this study to examine the health disparities in well child prevalence.

Methods We examined data on children born between 2007 and 2009 in 2010/2011. Using the primary level of service (LOS) procedure codes: 99381, 99382, 99391, and 99392 (evaluation and management codes), we obtained 69,447 visit records (11,374 patients) The health disparities by race and insurance status were examined using Chi squared statistic and multivariable logistic regression.

Results A significant racial/ethnic disparities was observed: Caucasians (68.1\%) relative to African Americans/Blacks (46.1\%), Asians (66.3\%), Hawaian/PI (53.4\%), and some other race $(52.4 \%)$ were more likely to meet the recommended schedule, $\chi^{2}(7)=2,800$, $p<0.0001$. Similarly, higher compliance was associated with commercially insured patients $(73.4 \%)$, relative to Medicaid $(45 \%)$ or uninsured/Nemours subsidized (38.3\%), $\chi^{2}(2)=4,700, p<0.0001$. Compared with Caucasians, AA/Blacks were 60\% (Prevalence Odds ratio $[\mathrm{POR}]=0.40,95 \% \mathrm{CI}, 0.39-0.42)$, while Asians were $8 \%(\mathrm{POR}=$ $0.92 .95 \% \mathrm{CI}, 0.82-1.12)$ less likely to comply with the schedule. After controlling for insurance status, racial disparities was lowered, and AA/blacks were $42 \%$ less likely to comply compared with Caucasians, adjusted $\mathrm{POR}=0.58,99 \% \mathrm{CI}, 0.55-0.61$; and uninsured $/$ Nemours subsidized were $77 \%$ less likely to adhere to schedule relative to the commercially insured patients, adjusted POR, 0.23 , 99\%CI, 0.21-0.26

Conclusions Racial disparities exist in "well infant visit", and was not completely removed after adjustment for insurance staus which is known to influence access and care utilization.

\section{COMPARING THE EFFICACY OF TOPICALSUCRALFATE VERSUS TOPICAL ZINC OXIDE IN DIAPER DERMATITIS, A RANDOMIZED DOUBLE BLIND STUDY}

doi:10.1136/archdischild-2012-302724.0380

N Sajjadian, M Kadivar. Pediatric, Tehran Medical University, Tehran, Iran

Diaper dermatitis is one of the most common skin disorder during infancy. Different modality of treatment is suggested. Sucralfate 